\title{
Estudos do Software (software studies) e a cul- tura da mobilidade contemporânea
}

\author{
Brett Stalbaum ${ }^{1}$ \\ Jane de Almeida ${ }^{2}$ \\ Cicero da Silva ${ }^{3}$
}

\begin{abstract}
Resumo: O objetivo do presente artigo é analisar os sentidos conceituais dos processos computacionais e de que forma eles se relacionam e afetam, ou até mesmo constituem, novas formas de processos comunicacionais, provocando modificações no âmbito das teorias da comunicação.O texto apresenta questões relacionadas à desterritorialização dos espaços formais das fronteiras físicas da informação, e propõe uma reflexão baseada em uma análise das mídias locativas em relação aos pesquisadores que criam suas obras baseadas na Internet a partir da utilização desses sistemas em seus trabalhos. O artigo apresenta a metodologia do Software Studies para analisar quatro projetos de mídias locativas: HiperGps, Walkingtools, HiperGeo e Gun GeoMarker, que abordam questões sobre espaço e tecnologia de georeferenciação por meio de aparelhos celulares, com o objetivo de pensar a territorialidade do acesso à informação digitalizada e suas representações como processos comunicacionais.O artigo especula acerca das questões sobre espaços e territórios, sobre a tecnologia dos servidores móveis que apontam para problemas com os quais os estados terão de lidar no futuro: em que espaço físico ficarão "hospedados" os "dados" de algum projeto ou sistema de informação e qual Estado terá a responsabilidade pela hospedagem, transferência e acesso aos dados?
\end{abstract}

Palavras-chave:Estudos do Software. Mídia digital. Cultura digital. Mobilidade. Mídias locativas.

Abstract: The main goal of this article is to analyze some of the conceptual meanings of
computational processes and how they relate and affect or even constitute new forms of
communication processes, in some cases changing the scope of communication theories.
The articlepresents questions related to the deterritorialization of the formal spaces of
the physical frontiers of information and proposes a reflection based on an analysis of
the locative media in relation to the researchers who create their works based on the In-
ternet from the use of these systems in their own works. The article presents the Software
Studies methodology to analyze four locative media projects: HiperGps, Walkingtools,
HiperGeo and Gun GeoMarker, thataddress questions about geo-referencing space and

1 Professor Associado, pesquisador e coordenador do curso de Design especulativo na Universidade da Califórnia, San Diego (UCSD). E-mail: stalbaum@ucsd.edu

2 Doutora em Comunicação e Semiótica pela PUC-SP, com pós-doutorado em Artes pela Universidade Harvard. Professora e coordenadora do Laboratório de Artes Cinemáticas e Visualização do PPG em Educação, Arte e História da Cultura da Universidade Mackenzie. E-mail: janedealmeida@post.harvard.edu

3 Doutor em Comunicação e Semiótica pela PUC-SP, com pós-doutorado em Estudos do Software pela UFRJ, e Universidade da Califórnia UCSD). Professor e coordenador adjunto do NTC de Telessaúde na UNIFESP. E-mail: csilva@weber.ucsd.edu 
technology through cellular devices, in order to think about the territoriality of access to information and its representations as communicational processes. The article also speculates about issues related to spaces and territories, about mobile server technology that point to problems that National States will have to deal with in the future: in what physical space will the "data" of any project or system be "hosted"? What kind of information and which National State will be responsible for hosting, transfer and access this data?

Keywords: Software Studies. Digital media. Digital culture. Mobility. Locative media.

\section{Introdução}

Os Estudos do Software, ou Software Studies, constituem um campo recente de pesquisa que abrange artes, tecnologias, comunicação e cultura no geral. Fundado em 2006 pelo pesquisador inglês Matthew Fuller e pelo teórico alemão Friedrich Kittler, o objetivo central do campo é compreender os impactos da utilização dos softwares nas sociedades e culturas contemporâneas. Em artigo publicado em 2010, o pesquisador Lev Manovich, diretor do grupo de Software Studies nos EUA, estabeleceu uma análise empírica do que teria sido o efeito da introdução dos NURBS (Non-uniform rational basis spline), uma técnica matemática de representação gráfica de linhas curvas empregada por alguns softwares nos objetos arquitetônicos recentes. Manovich defende que a arquitetura contemporânea de Zaha Hadid, por exemplo, não teria sido possível se não fossem as possibilidades de representações criadas por meio do processamento computacional (MANOVICH, 2010, p. 108-133) [1]. Seguindo a metodologia desenvolvida por Manovich, Fuller e Kittler, o presente artigo analisa um fato recente no campo das mídias locativas. Há 11 anos, em 2007, a empresa Nokia desenvolveu pela primeira vez um sistema de protocolos que ativava um servidor web em alguns celulares que processam dados de forma aproximada a de um computador, com velocidades em torno de $800 \mathrm{Mhz}$, o equivalente a um processador Pentium II da Intel dos anos 1990. A ideia de se poder armazenar conteúdos de sites inteiros em celulares e de tornar portáteis os conteúdos de todo um portal ou website de uma empresa, trouxe à tona algumas questões pertinentes sobre a manutenção de conceitos chaves que giram em torno das teorias das redes. A primeira questão que esse fato tocou foi o da radicalização da desterritorialidade. Em outras palavras, se na web 1.o, aquela dos anos 1990, já se falava no problema de que 
um servidor pode hospedar conteúdos impróprios, sendo instalado fora do país, hoje podemos perguntar como vem se dando a configuração teórica acerca de servidores que andam pelo mundo, ou mesmo dentro de seus países, sem que seja possível localizá-los precisamente em algum espaço físico, com endereço, telefone, e-mail, cidade (indicadores da era 1.0) [2]?

Atualmente, a maior parte dos servidores que hospedam os dados que são acessados on-line e em tempo real, estão localizados em algum espaço fisicamente identificável e que, normalmente, dependem de redes de energia elétrica, água para refrigeração de seus processadores e equipamentos de controle da temperatura do ar para que os computadores mantenham sua performance. Esta é uma condição física da rede que ainda persiste. Contudo, se for possível andar por aí com telefones celulares rodando serviços de servidores que hospedam blogs e wikis, como se dará o controle e a manutenção de serviços de redes de troca de informação? De que forma as redes serão organizadas se esse formato de troca de arquivos começar a ser formalmente utilizado e liberado pelas operadoras de telefone celular? De que maneira a sociedade lidará com essa desmaterialização dos objetos de arquivamento e compartilhamento de dados a partir de pequenos sistemas que ficarão hospedados em seus bolsos ? Há diferenças entre um servidor estar hospedado em um celular com acesso à Internet, e um celular que só acessa a Internet por meio de uma conexão com a Internet, acessando um servidor que está fisicamente localizado em um stack dentro de um datacenter, com IP fixo e endereço localizável. Uma delas é que dificilmente conseguimos localizar o "emissor" da informação, pois é complexo identificar a localidade física do servidor computacional. Diante dos cenários recentes ligados à propagação de informações inverídicas, normalmente distribuídas por meio de sistemas que não são rastreáveis e que estão hospedados em outros países, de que forma essas tecnologias tendem ou não a ampliar o problema da confiabilidade das informações?

\section{Software Studies: uma introdução}

O computador afetou várias representações culturais e tem sido pensado como elemento gerador de questionamentos do processo de criação e difu- 
são das informações e imagens, assim como é objeto de conexão entre pessoas, dados e processos. Esses processos têm sido amplamente estudados por autores nos campos da cultura e da comunicação, mas existem ainda áreas pouco exploradas e que podem deslocar as questões relacionadas ao computador para outros universos que são os das representações comunicacionais advindas da cultura do software. Segundo Lev Manovich, em seu livro Software Takes Command, "Software is the engine of contemporary societies" [3] (MANOVICH, 2008, p.7); atualmente os processos sociais, em sua grande maioria, são regulados via software e, por sua vez, pelos computadores. Como consequência, pode-se afirmar que não há mais tráfego em grandes capitais do mundo que não funcione e seja regulado por softwares e computadores, assim como não há telefones que não operem ou demandem programações complexas via software, e mesmo controles de torres aéreas que não funcionem e se auto-regulem via emaranhados complexos de informações, entre várias outras esferas sociais que vão da administração de estoques de supermercados à reação do público em uma eleição. Tudo passa a sofrer influência de processos algorítmicos e as decisões se tornam dependentes de análises desses resultados complexos promovidos pelo software.

Nesse sentido, o presente artigo propõe também um estudo preliminar das linguagens que operam o processamento computacional nos âmbitos da mídia e da comunicação e o seu impacto e influência nas mais variadas áreas culturais da sociedade. $\mathrm{O}$ artigo procura também deslocar o debate, que geralmente se dá por meio da computação ou das "novas tecnologias" (que são computacionais), para as relações que envolvem o computador como elemento de pesquisa e o inserem na esfera denominada mobilidade, apresentando uma diferença, pois assim que os dispositivos móveis passaram a operar com a lógica do processamento computacional, um novo evento se realiza: o fato de que o celular pode ser ele mesmo um servidor, podendo ser considerado um fato de uma "era da pós-mobilidade".

O deslocamento informacional do servidor físico para servidores móveis aciona uma discussão em torno da linguagem e das representações da máquina, não mais partindo da discussão sobre as meras formas que as linguagens do processamento operam, e sim acerca das formas como a sociedade se apropria e inventa outros usos para o sistemas computacionais. Como consequência, acre- 
dita-se que será necessário reposicionar as questões que hoje envolvem conceitos como "virtual”, "hibridismo", "interatividade", "simulação", entre outros - que foram criados e resgatados de outros campos para configurar o universo da máquina computacional ou os mecanismos das "novas tecnologias".

\section{Antecedentes: Estudos do Software}

Estudos sobre o software ou estudos culturais do software como linguagem das sociedades contemporâneas existem há algum tempo, porém, não haviam sido sistematizados como campo de pesquisa. A palavra software, normalmente associada à área computacional ou à engenharia, foi poucas vezes associada às influências culturais e sociais provenientes do uso dos processos computacionais - que por sua vez são mediados pelo software.

Um dos primeiros pensadores a iniciar um debate sobre a importância do software nas sociedades contemporâneas foi Matthew Fuller, professor do Goldsmiths College em Londres. Fuller organizou, em fevereiro de 2006, o primeiro grupo e, posteriormente, o primeiro workshop sobre Software Studies. Durante o workshop ficou estabelecido o uso da expressão Software Studies [4] para fazer referência ao estudo do impacto do software nas culturas e nas sociedades contemporâneas. O campo de análise do projeto de Fuller estabelecia que o software deveria ser visto não como mero coadjuvante nas alterações iniciadas pela cultura do computador, mas como protagonista de inúmeras modificações, entre elas comportamentais (como viver com um celular e ser informado em "tempo real" dos acontecimentos), além de visuais, através da introdução de softwares de manipulação de imagens estáticas e em movimento que acabaram criando novos padrões estéticos. Isso sem contar com os aspectos quase inconscientes associados aos softwares, como quando se dirige um carro pelas ruas das grandes cidades com monitoramento por algoritmos que alteram o fluxo e a velocidade, controlam os semáforos, indicam a melhor rota (agora com a introdução de GPSs em tempo real nos celulares, Wwaze), ou quando no supermercados há análise de compras para abastecer bancos de dados que orientam as vendas, além dos cancelamentos de fornecedores em tempo real e a compra de novos produtos. 
Baseados nas premissas de Fuller, os pesquisadores Lev Manovich,professor da City University of New York (CUNY), e Noah Wardrip-Fruin, professor da Universidade da Califórnia de Santa Cruz (UCSC), iniciaram um projeto para criar, nos Estados Unidos, o primeiro grupo de Software Studies. Em maio de 2008 foi organizado, pela primeira vez, um workshop sobre o tema que contou com a presença de mais de 40 pesquisadores de áreas afins, entre eles o próprio Fuller e o reconhecido teórico idealizador da ideia na Alemanha, Friedrich Kitler. Nesse evento também foi lançado o grupo de Software Studies no Brasil, cujo conteúdo está no site www.softwarestudies.com.br.

Durante o workshop puderam ser avaliados vários projetos que tratam das alterações criadas pelo software na cultura e na sociedade, dentre eles, sistemas de geração de imagem de alta complexidade através de linguagens especialmente dedicadas à visualização, como foi o caso do Processing [5], linguagem compilada, criada por Ben Fry e Casey Reas, que permite produzir imagens e animações baseadas em protocolos de acesso ligados à estética dos bancos de dados computacionais. Outro sistema que vem sendo utilizado, principalmente na área de ensino de arte e de comunicação digital, é o projeto OpenFrameworks, criado por Zachary Lieberman [6], e que permite a compreensão, de forma bastante simples, de linguagens complexas.

Os estudos do software acreditam que o software tem afetado o sujeito desde ofinal do século XX de forma irreversível e profunda. Apesar de se ter uma ideia sobre os processos mediados pelo software, ainda são incipientes as formas de análise do impacto de sua cultura no campo comunicacional, que hoje parece investido pela ideia de "mídia". O que se observa com mais frequência são análises dos efeitos daquilo que aparece nas telas dos computadores dos usuários ao redor do mundo, mas pouco se tem analisado o que está por detrás dessas pirotecnias que geram essas imagens, animações ou mesmo que permitem uma conexão em "rede social" de comunidades inteiras. Este "detrás" tem o sentido de black box, como foi teorizado por Vilém Flusser a respeito da câmera fotográfica (FLUSSER, 2000, p.35). Esse artigo é derivado de um projeto mais amplo, coordenado por Lev Manovich, na Universidade da Califórnia, em San Diego, denominado Analítica Cultural (Cultural Analytics), que faz referência ao uso de máquinas computacionais de alta 
performance em projetos nas áreas de ciências sociais e humanidades. Um dos problemas analisados pelo projeto diz respeito à difícil e intricada relação entre os pesquisadores das humanidades e as grandes quantidades de dados sem estrutura, de difícil sistematização e, consequentemente, precária análise. Tais dados podem ser encontrados em diversas formas, como jornais históricos, livros, dados de eleições, fragmentos arqueológicos, conteúdos de áudio ou vídeo, o que dificulta ainda mais a sua leitura, visualização e manutenção. Com a computação de alta performance é possível não só digitalizar o conteúdo a ser analisado, mas também visualizá-lo de forma mais dinâmica e produzir relações e buscas de forma mais rápida, isso sem contar com a possibilidade de busca de elementos dentro de arquivos. Imagine que algum pesquisador de cinema queira saber em quantos filmes ou em que filmes determinada cidade aparece. Atualmente seria necessário somente um comando (algoritmo) de rastreamento que varreria todos os filmes e contaria, em segundos, todas as vezes em que tal cidade apareceu em cena, caso todos os filmes estivessem em um banco de dados. A partir de possibilidades como esta, estudos culturais já pensam sobre a influência que determinadas tecnologias terão sobre a informação, sobre o processo de emissão e recepção, sobre a esfera da comunicação como um todo.

\section{A era da pós-mobilidade}

Pensando na influência dos dados a serem processados no campo da comunicação móvel, no que diz respeito aos aparelhos celulares, é que este artigo esboça algumas questões. Como apontado anteriormente, vários telefones celulares ou aparelhos móveis, antes dedicados somente à fala, foram equipados ao longo dos anos com sistemas e hardwares que o tornaram um elemento próximo do computador. Aparelhos que antes possuíam alguns meros transmissores, antenas e alguns leds, passaram a ganhar microprocessadores com capacidades que superavam, em muito, os computadores do final dos anos 1990. Aliada a essa capacidade de processamento, os anos 2000 também viram surgir aparelhos móveis celulares equipados com GPS (para geoposicionamento global) e também aptos a receber e a visualizar conteúdos da Internet, receber e-mails através do acesso via browser ou da instala- 
ção de softwares de administração de correio eletrônico, como no caso dos telefones blackberry, que modificaram a forma como as pessoas começaram a lidar com a carga diária de e-mails relacionados ao trabalho. Além disso, vários celulares, além de serem meros aparelhos para processar dados, começaram a ser objetos de produção de dados a partir de seus próprios recursos: câmera fotográfica, filmadora, editor de vídeo, de áudio, de projeção, de preparação de documentos, de apresentações, de edição de imagens e, em alguns casos, celulares que permitem que se programe programas de computador e que se execute e se teste, neles mesmos, o que se está programando, tornando o programador independente do próprio aparato computacional tradicional como o desktop ou o notebook. Se hoje é comum os celulares se tornarem produtores de dados, ainda é remoto, e somente acessível a poucas pessoas, o fato de eles serem usados como processadores, mas acredita-se que este fato se tornará comum em poucos anos para grande parte da população.

\section{Software Studies em ação: ativismo, walkingtools e localização}

Os argumentos acima são frutos de reflexões provenientes de experimentos culturais e mídia artísticos dos autores do artigo, além de outros projetos acompanhados pelos autores. O primeiro deles data do final do ano de $2009 \mathrm{e}$ início do ano de 2010, a partir da realização de um projeto denominado Transborder Immigrant Tool [7], dos artistas Brett Stalbaum, Ricardo Dominguez e Micha Cárdenas. O projeto foi alvo de intenso debate na mídia norte-americana e mexicana, tendo ressoado de forma agressiva nos departamentos aos quais os artistas estão vinculados como professores na Universidade da Califórnia, em San Diego (UCSD). O projeto tinha a intenção de prover um programa a ser instalado em celulares que custam em torno de 10 dólares, com o objetivo de auxiliar imigrantes ilegais, que tentam atravessar a fronteira dos EUA com o México, a localizar água potável e, com isso, evitar a morte diária de dezenas de pessoas que adentram uma área desértica. Com a utilização de um aparelho celular dotado de GPS e de um software criado para esse fim, as pessoas poderiam encontrar água em locações próximas em locais vastos, sem trilhas claras para seguir. O sistema funcionou bem e permitiu que algumas vidas fossem salvas. Portanto, o objetivo 
do grupo foi alcançado. No entanto, para a segurança norte-americana e parte da mídia o que o coletivo propõe é crime federal. Entretanto, para um outro tipo de recepção, trata-se de um ato humanitário de primeira grandeza.

Contudo, a questão que pensamos merecer toda a nossa atenção é o fato de um software e um aparelho celular dotado de GPS poder servir para um ato político que coloca em questão as formas de tratamento aplicadas aos imigrantes ilegais que tentam uma vida melhor ao cruzar a fronteira.

$\mathrm{O}$ segundo projeto na área da mobilidade foi desenvolvido pelos autores durante os anos de 2008 e 2009, denominado Walkingtools. Este projeto inclui dois softwares criados especialmente para a produção de arte mídia móvel, o HiperGPS e o HiperGEO.

O website Walkingtools é um espaço aberto para hospedagem de softwares relacionados com projetos de arte ou educação que perpassam várias linguagens, plataformas e disciplinas que compartilham padrões para entrega de conteúdo e administração de dados de GPS através da definição da localização geográfica dos celulares. Além disso, o site walkingtools.net documenta e provê recursos para uma variedade de projetos independentes, mesmo que não interrelacionados.

Imagem 1:Imagem do website do projeto

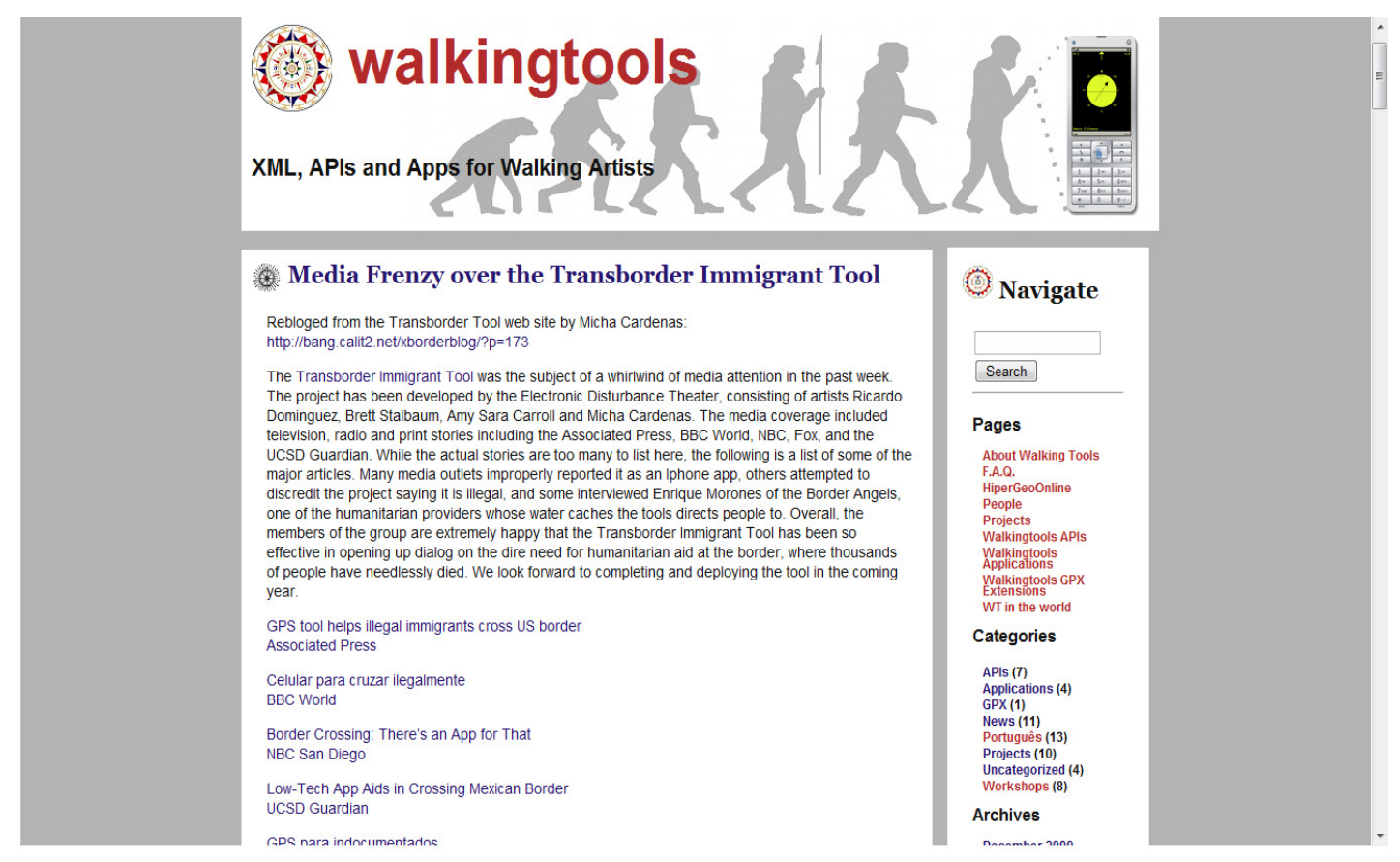

Fonte: www.walkingtools.net 
A plataforma Walkingtools é apresentada como um "metaprojeto", abrigando APIs e projetos de outros colaboradores. É comum observar que existe certa confusão na interpretação do que vem a ser o projeto. Essa constatação surgiu quando, no início do ano de 2010, o projeto foi acusado, por alguns representantes do partido Republicano dos Estados Unidos [8], de ser um potencial distribuidor de tecnologias que permitiam a entrada de imigrantes ilegais, pois com o sistema é possível construir e referenciar pontos geográficos e associá-los a algum elemento físico ou virtual qualquer através do GPS.

O terceiro projeto, anteriormente citado e chamado HiperGPS, permitia que instituições e indivíduos pudessem desenvolver seus próprios tours interpretativos, conceituais ou poéticos através do GPS, tanto de aparelhos dedicados quanto de aparelhos celulares dotados com essa tecnologia. O software HiperGEO [9] era uma plataforma interligada que permitia a sincronização dos dados de GPS ligados às mídias com servidores web. O sistema foi apresentado pela primeira vez no ano de 2009 na exposição Landscape 2.o [10], com a curadoria de Sabine Himmelsbach, na galeria Edith Russ Site for Media Art. O projeto HiperGEO criava rotas através do posicionamento geográfico e em determinadas posições geográficas (latitudes e longitudes) o sistema ativa imagens e sons. Cada usuário poderia criar suas rotas e quando alguém passasse pela localidade teria acesso aos dados. Além disso, no sistema HiperGEO era possível que os dados associados às posições geográficas pudessem ser enviados para o servidor do projeto e compartilhados por outras pessoas. Ou seja, se o usuário criasse um poema sonoro que estava espalhado por coordenadas geográficas na cidade de Chicago e quisesse compartilhar seu poema com outros usuários de sistemas de localização geográfica, ele poderia enviar os dados, através da opção "sincronizar", para o servidor de web do projeto. O sistema também permitia localizar, por proximidade, outros projetos desenvolvidos com o HiperGEO através das coordenadas geográficas (latitude e longitude). 


\section{LUMINA}

Estudos do Software (software studies) e a cultura da mobilidade contemporânea

Imagens 2 e 3: Softwares HiperGPS e HiperGEO

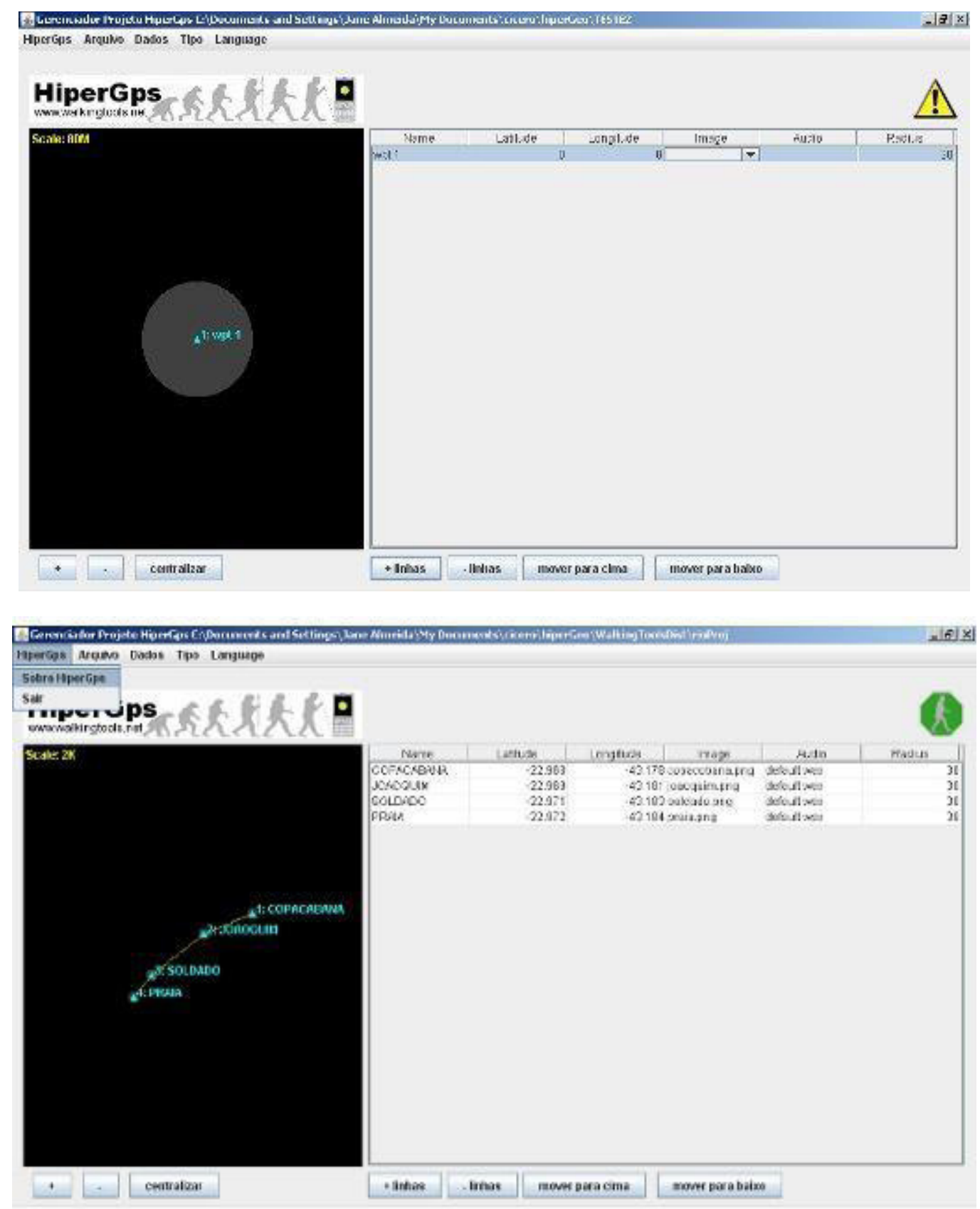

O projeto Gun Geomarker foi desenvolvido entre 2013 e 2016 por Brett Stalbaum, um dos autores deste artigo. O projeto tinha como objetivo: a) o desenvolvimento de um app para geolocalizar os proprietários de armas nos Estados Unidos; b) mostrar no Google Maps a localização dos proprietários das 
armas; e c) criar uma visualização da base governamental pública dos registros de proprietários de armas em um mapa. Um propósito não intencional era também alertar os vizinhos de um proprietário de armas caso este decidisse comprar um arsenal, algo que não seria tão natural, vamos assim dizer, como foi o caso do franco atirador de Las Vegas que matou 58 pessoas [11].O projeto Gun Geomarker realizava algo bastante simples, mas que, na atualidade, pode servir de exemplo do poder da visualização de dados e do problema de se "mostrar" ou de se "publicizar" informações que, na verdade, já são e estão em domínio público. A base norte-americana de portadores de armas é, em diversos estados, pública. Ou seja, se você quiser saber quem tem uma arma na sua rua, é só consultar uma base de dados on-line. Essa base de dados é, diga-se de passagem, construída de maneira muito ruim, com extrema dificuldade de uso e acesso, pois, como é óbvio, não interessa que o Google ou algum outro buscador torne "pública" esta informação. Nesse sentido, para você saber se seu vizinho é ou não portador de um arsenal, ou se ele tem comprado centenas de armas nas últimas semanas, você terá que entrar em um site muito mal desenhado, com usabilidade perto do zero, e tentar achar o local de busca das informações. Os campos para você buscar essas informações também exigem pesquisas "cruzadas" como, por exemplo, você precisa saber o endereço exato do seu vizinho, seu nome completo, a data de nascimento etc., para ver as informações. Contudo, existe, para programadores um pouco mais avançados, uma forma de fazer o download dessas informações. Com esse download em mãos é possível cruzar os dados dos endereços dos proprietários de armas com o Google Maps, por exemplo, e pronto, você poderá ver no mapa do aplicativo aquilo que estava praticamente escondido em um site de consulta pública. Outro caso bastante parecido aconteceu recentemente no Brasil quando jornalistas da Gazeta do Povo, de Curitiba, decidiram publicar os salários acima do teto constitucional dos representantes do Ministério Público e do Tribunal de Justiça do Paraná [12]. Esses dados, como é sabido, são de domínio público, ou seja, qualquer cidadão pode ter acesso. Contudo, o fato de um jornal ter publicado os dados os tornou "evidentes", ou "visualizáveis", de maneira a provocar uma reação contrária por parte dos representantes do judiciário do Paraná. No caso, os membros do judiciário paranaense entraram com dezenas de 
ações conjuntas contra os repórteres do jornal, pedindo indenização por danos morais para dados que já estavam em domínio público, disponíveis nos websites dos sistemas de transparência dos próprios órgãos do governo. É de se estranhar que os membros do judiciário paranaense, assim como os proprietários de armas nos Estados Unidos, não tenham processado também as leis de transparência dos estados e seus respectivos canais de divulgação, normalmente endereços eletrônicos com consulta bastante complexa à sua base de dados.

Imagem 4: Website Gun Geomarker

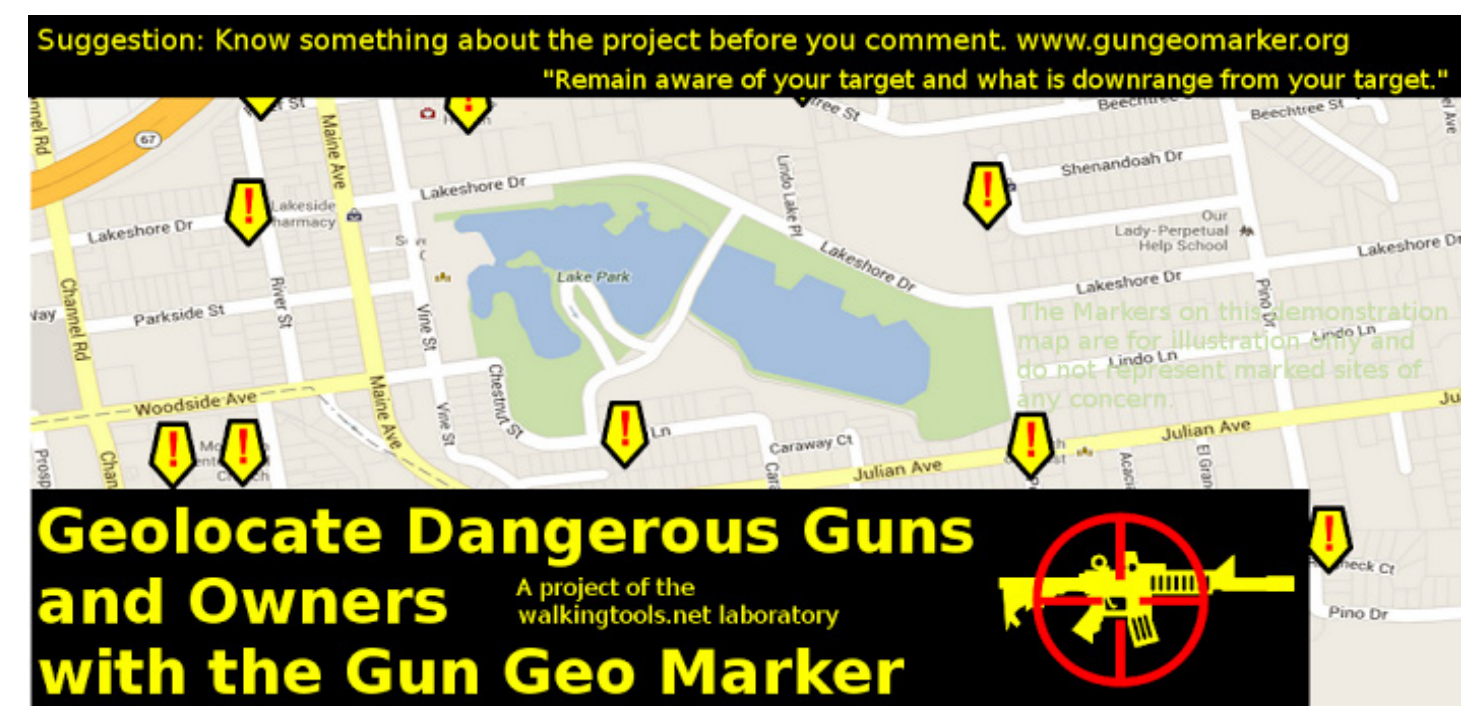

Fonte: https://gungeomarker.wordpress.com/.

Como era de se esperar, assim como aconteceu no judiciário paranaense, a reação ao projeto Gun Geomarker foi intensa. Foram dezenas de pedidos de processos contra o autor do projeto (que foram todos defendidos pela Universidade da Califórnia, San Diego - UCSD - sem custos para o professor); enfim, a pressão dos defensores de armas de fogo nos Estados Unidos contra o projeto foi tão intensa que o Prof. Brett Stalbaum decidiu remover o acesso público ao aplicativo [13]. Hoje em dia, mostrar um dado já público pode ser interpretado como um afronta ou mesmo como uma ameaça. Contudo, é interessante observar que, se assim o é, qual o motivo de se ter "leis de transparência” se, no final das contas, a sociedade que paga as contas desses sistemas caros não consegue "visualizar” as informações? E se, quando elas 
são "visualizadas", supostamente "ofendem" a dignidade dos listados nos sistemas?

\section{Arqueologias da mobilidade e futuros da pós-mobilidade}

O conceito de mobilidade tem relação direta com o espaço geográfico no qual algum indivíduo está inserido. Em outras palavras, falar de uma cultura móvel ou mediada por dispositivos de localização tem imediata conexão com a espacialidade física territorial, o que nem sempre é lembrado quando se pensa nesta modalidade. Contudo, quando um sistema de distribuição de informações está geograficamente localizado em um suporte que pode não ser geograficamente localizável, entra em jogo um processo de desidentificação de um conceito em relação a outro, ou seja, a mobilidade pode não ter relação direta com espaço geográfico. Essa perspectiva foi apontada por Eric Kabisch (2009) e por Rita Raley (2009) em suas apresentações nos painéis em que foram discutidas as tendências denominadas de "after mobile media" em "The present and future of humanist inquiry in the digital field". Segundo definiu Kabisch, nos próximos anos mais e mais pesquisadores e formuladores de políticas de acessibilidade à informação deverão se deparar com eventos impossíveis de serem controlados em termos de território, e esse controle não deriva das forças de controle, tais como aquelas disseminadas em teorias como as de Michel Foucault, e nem mesmo das estruturas de poder, mas sim de eventos pura e simplesmente automatizados criados pelas novas formas de programar, acessar, recuperar e visualizar os dados.

Percebe-se, por meio da mobilidade tecnológica, uma questão que enriquece o debate sobre nacionalidade e nacionalismo, nos moldes com que Benedict Anderson afirmava sobre o imaginário nacional: as comunidades imaginárias se fortalecem não pela nacionalidade instituída oficialmente, mas por aquela compartilhada pelo software, independente de onde seu servidor esteja localizado (ANDERSON, 1991). Este fenômeno pode também ser verificado pelas assinaturas de bancos de dados de filmes como Netflix, Amazon e Hulu, que lutam para que as assinaturas fiquem restritas às identidades nacionais, e logo são 
burladas por servidores fantasmas e VPNs (Unblock US, Unlocator, VPN Express entre outras) [14].

Essas questões estão ainda para serem elaboradas e nem se sabe se as grandes corporações detentoras das operadoras de telefonia móvel autorizarão ou bloquearão as troca de dados, mas o que interessa é perguntar agora como se poderia responder a estas questões de forma prática e direta. Será um dia possível alguém andar com o seu site em seu bolso? Será possível alguém um dia fazer download, via protocolos de Internet, de músicas que estão hospedadas em meu telefone celular, ou melhor, a partir do site que está hospedado em meu telefone celular? E se for um site pornográfico? Bem, você poderá dizer: ora, como assim, é só perguntar à operadora quem é o detentor da linha $\mathrm{X}$ e saber que foi ele que postou, trocou ou hospedou um site, não é? Bem, então lembre da facilidade que é comprar um chip pré-pago de uma operadora ou como é simples utilizar hot spots $w i$ - $f$ sem controle de senha, para telefones celulares com dispositivo para acesso às redes sem fio.

Na imagem abaixo, o antigo website do projeto Mobile Web Server, da Nokia, com detalhes para a utilização, instalação e procedimentos de uso para a hospedagem de um website em seu telefone celular. O site www.opensource. nokia.com/projects/mobile-web-server/index.html era periodicamente atualizado e as ferramentas estavam sendo ampliadas diariamente no início dos anos 2000. Acredita-se que num futuro próximo o que veremos são sistemas de distribuição da informação em rede (as chamadas nuvens, ou grids) que farão a interconexão entre todos os dispositivos móveis, gerando um "grande servidor" de rede distribuído. Além dos impactos listados acima, e diante das notícias recentes ligadas às corporações que controlam a maior parte das redes sociais, como Twitter e Facebook, que têm sido acusadas por inúmeros setores da sociedade civil de distribuir notícias falsas, as chamadas fake news, é importante observar que se sistemas de servidores começarem a funcionar sem geolocalização (necessidade da presença física de um computador conectado a uma rede fixa) a distribuição da informação que hoje já é difusa, muito provavelmente se tornará impossível de se identificar o local de onde partiu a sua distribuição [15]. 
Imagem 5: Primeiro servidor web para aparelhos celulares em sistema Symbian da Nokia.

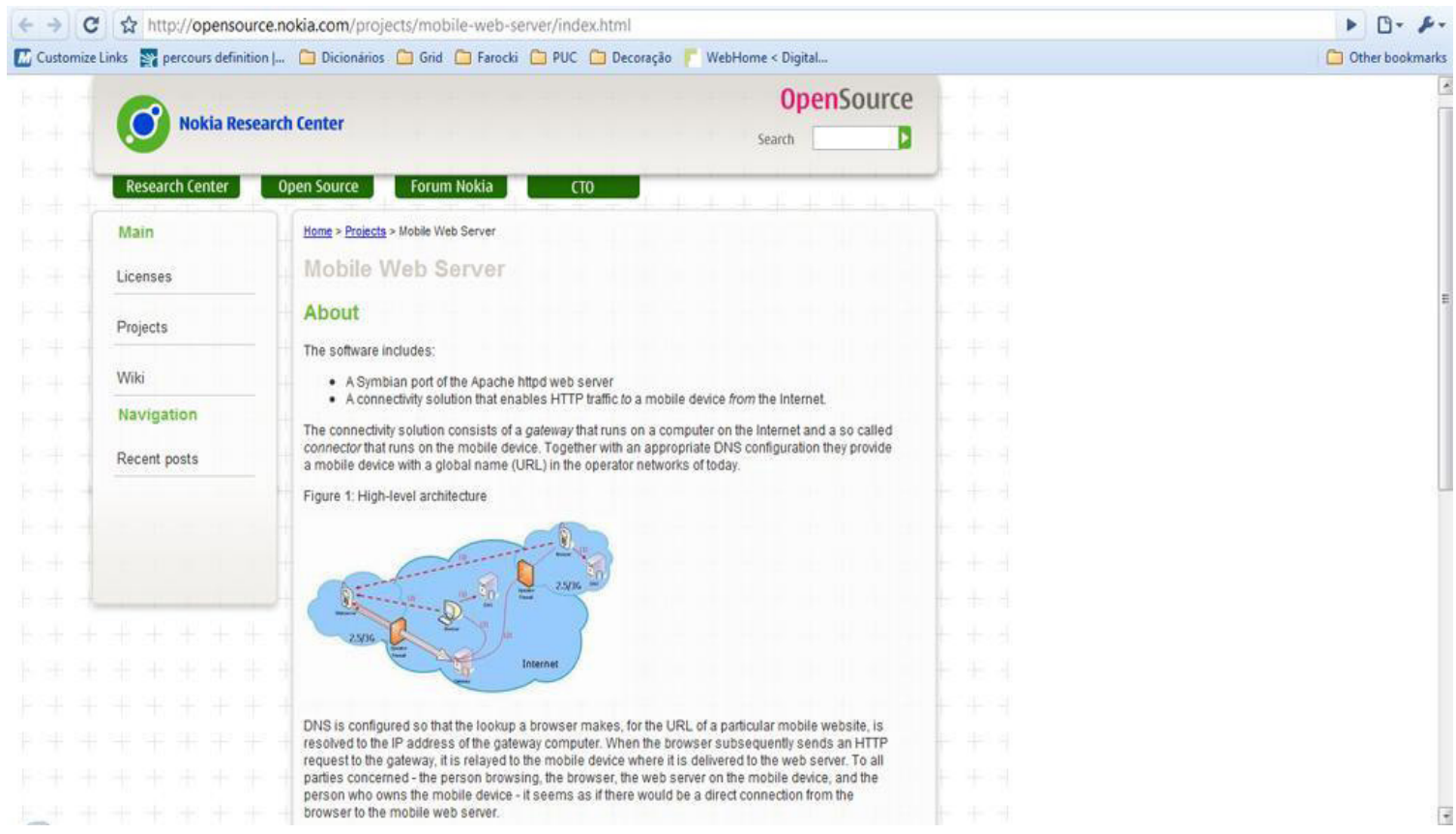

Em relação aos futuros problemas que esses sistemas trarão aos países, em termos de controle de acesso e distribuição de dados, a imagem abaixo representa o poder que sistemas e websites hospedados poderão ter em termos políticos e ideológicos.

Imagem 6: Representação hipotética de uma situação na qual cada indivíduo poderá "portar" um servidor web em seu próprio celular e ser capaz de postar em tempo real notícias, vídeos e mídias sem ser rastreado.

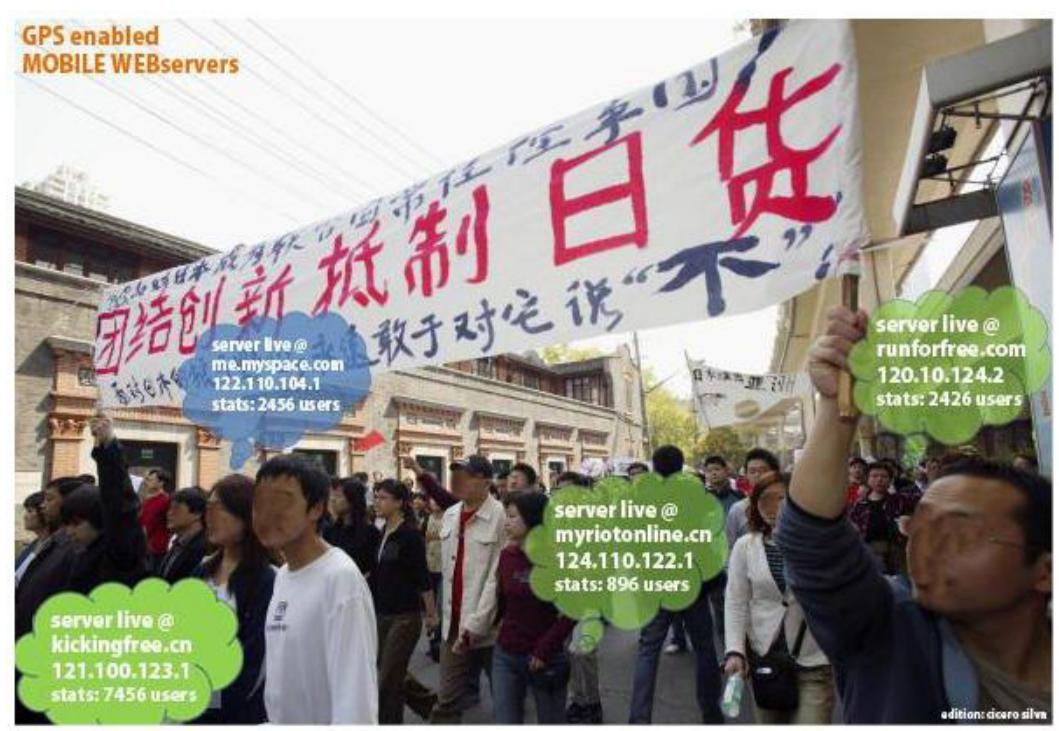




\section{Considerações finais}

Os quatro projetos analisados, Walkingtools, HiperGEO, HiperGPS e Gun Geomarker, foram elaborados a partir das particularidades dos sistemas de distribuição da informação contemporâneos, com a intenção de pensar os limites geográficos dos dados [16]. As nuvens, por mais que se diga que elas "guardam" nossas informações em algum espaço etéreo, estão muito bem localizadas em prédios físicos que demandam uma série de infraestruturas para funcionar. A possibilidade de se pensar em formas mais autônomas de distribuição da informação na cultura da mobilidade pode vir a modificar a maneira como a sociedade vai guardar sua produção cultural digital, produzida massivamente e hoje hospedada em sistemas físicos que não lembram em nada uma nuvem, apesar do seu nome. E essas outras possíveis configurações poderão também criar outros padrões de acesso aos dados, mais instáveis, mas também mais próximos fisicamente dos usuários.

\section{Notas}

[1] Ver Lev Manovich em PERISSINOTTO, P.; BARRETO, R. Teoria Digital. Trad. de Cicero Inacio da Silva e Jane de Almeida. São Paulo: Imprensa Oficial, 2010, p. 108133. Disponível em: <http://lab.softwarestudies.com/2011/11/teoria-dos-nurbs.html>. Acesso em: 12 dez. 2018.

[2] O último livro de Benjamin Bratton trata desse tema a partir do problema das "pilhas" de servidores de rede, aos quais o autor denomina como "stacks". Bratton propõe uma análise do conceito de stack, relacionando-o com o de black box dos computadores e, nesse sentido, assim como o computador passou grande parte do século XX sendo criticado por ser uma "caixa preta", cujos processos não eram conhecidos nem transparentes, o mesmo então se aplicaria aos computadores ligados em nuvem, que funcionam em grandes galpões em localidades isoladas, preenchidos por grandes pilhas com milhares de processadores que armazenam nossos dados. A essa nova realidade, Bratton deu o nome de "black stack". Ver mais em BRATTON, Benjamin . The stack. Cambridge: MIT Press, 2016.

[3] O software é a máquina das sociedades contemporâneas. (Tradução livre).

[4]Ver Matthew Fuller. Software Studies: a lexicon. Cambridge: MIT Press, 2008.

[5] Ver REAS, Casey ; FRY, Ben . Processing. Cambridge: MIT Press, 2008.

[6] Ver www.openframeworks.cc

[7] O projeto está documentado nos seguintes sites: www.walkingtools.net e http:// bang.calit2.net/xborder . 
[8] O canal Fox News apresentou uma reportagem completa sobre o caso, assim como outros radicais discutiram intensamente os desdobramentos que o projeto poderia ter em termos de desobediência civil. Disponível em: <https://bit.ly/2Esxoft >. Acesso em: 13 dez. 2018.

[9] A documentação sobre o projeto está em https://www.researchgate.net/publication/281500369_HiperGeo_HiperGps_hands_on.

[10] O video com explicações sobre o projeto pode ser encontrado em http://vimeo. com/6336941.

[11] Disponível em: <https://g1.globo.com/mundo/noticia/atirador-de-las-vegas-possuia-42-armas-entre-sua-casa-e-o-hotel.ghtml>. Acesso em: 13 dez. 2018.

[12] Disponível em: <http://g1.globo.com/pr/parana/noticia/2016/o6/jornalistas-podem-ser-condenados-por-faltarem-audiencia-no-parana.html $>$. Acesso em: $13 \mathrm{dez}$. 2018.

[13] O canal Fox News, rede de televisão oficial do partido Republicano, fez uma longa matéria sobre o projeto Gun Geomarker: http://www.foxnews.com/tech/2013/o7/11/ gun-geo-marker-app-tries-to-locate-homes-businesses-gun-owners.html.

[14] VPNs são as redes virtuais privadas que proveem acesso remoto ponto a ponto, o que significa dizer que qualquer usuário pode ter um "endereço" físico de um protocolo de Internet em qualquer país do mundo, permitindo que, ao navegar na Internet por meio de browser ou apps, o usuário engane os provedores de Internet e que o sistema simule que o seu computador está em outro país. Dessa forma, é possível assitir sites de vídeos sob demanda que só permitem acesso a certos conteúdos em determinados países, como é o caso da Netflix norte-americana.

[15] É importante salientar que os autores defendem o anonimato na rede (Internet). É sabido que a possibilidade de se ter uma garantia pública de que uma informação possa ser verificada a partir da indicação de um cidadão, sem que ele sofra qualquer forma de assédio ou constrangimento, é um dos pilares das democracias modernas e, nesse sentido, é importante que se criem mecanismos para a avaliação e posterior validação ou não das informações, com a respectiva tomada de decisão pela sociedade.

[16] O desenvolvimento deste artigocontou com apoio da FAPESP, por meio do programa BPE, processo número 17/20434-6.

\section{Referências}

ALMEIDA, J.etat. Passages on brazilian scientific cinema. Public Understanding of Science,v.2,2016.Disponívelem:<https://doi.org/10.1177/og63662516683638>. Acesso em: 12 dez. 2018.

ANDERSON, Benedict R. Imagined communities: reflections on the origin and spread of nationalism. New York: Verso, 1991.

AUGÉ, Marc. Não-lugares: introdução a uma antropologia da supermodernidade. Campinas: Papirus, 1994. 
BARNET, Belinda. The Erasure of Technology in Cultural Critique.In: Fibreculture Journal. Austrália. v. 09, n. 2, Jul./Dez, 2008. Disponível em: <http://journal.fibreculture.org/issue1/issue1 barnet.html > . Acesso em: Acesso em: 12 dez. 2018.

BOLTER, Jay David Bolter; GRUSIN, Richard. Remediation? Understanding New Media. Londres: MIT Press, 2000.

BRATTON, Benjamin. The stack. Cambridge: MIT Press, 2016.

BREA, José. La era postmedia. Acción comunicativa, prácticas (post)arísticas y dispositivos neomediales. Salamanca: Editorial Centro de Arte de Salamanca, 2002. Disponível em: <http://laerapostmedia.net/pedidos/LaEraPostmedia. zip >. Acesso em: 12 dez. 2018.

BUIANI, Roberta. Marginal networks: the virus between complexity and suppression.In: Fibreculture Journal, v. 4, n. 3, Jan./Jun, 2006. Disponível em: <http:// journal.fibreculture.org/issue4/issue4 buiani.html> . Acesso em: 12 dez. 2018.

FULLER, Matthew. Software studies: a lexicon. Cambridge: MIT Press, 2008.

FLUSSER, Vilém. Towards a philosophy of photography. Londres: Reaktion Books, 2000.

KABIBSCH, Eric. Mobile after-media, cultural narratives and the data imaginary. UC Irvine: Digital Arts and Culture, 2009. Disponível em: < $\underline{\text { http://escho- }}$ larship.org/uc/item/8nk172kc> . Acesso em: 12 dez. 2018.

LANDOW, George. Hypertext 3.o. Baltimore: Johns Hopkins UP, 2006.

MANOVICH, Lev. The language of new media. Cambridge: MIT Press, 2001.

. Estudos do software.In: PERISSIONOTTO, Paula; BARRETO, Ricardo (Ed.). FILE 2008 ooo ooo. São Paulo: IMESP, 2008, p. 144-156. Disponível em: $\quad$ http://lab.softwarestudies.com/2008/o8/estudos-do-software-por-lev -manovich.html>. Acesso em: 12 dez. 2018.

. Efeitos de escala nas novas mídias.In: PERISSIONOTTO, Paula; BARRETO, Ricardo (Ed.). FILE 2008 ooo ooo. São Paulo: IMESP, 2008, p. 12-22. Disponível em: <www.softwarestudies.com.br > Acesso em: 12 dez. 2018.

. Teoria dos NURBS.In: PERISSINOTTO, Paula; BARRETO, Ricardo (Ed.). FILE 1O. São Paulo: IMESP, 2009, p. 108-133. Disponível em: < http://lab. softwarestudies.com/2009/07/nurbs-theory-teoria-dos-nurbs-file-2009.html >. Acesso em: 12 dez. 2018.

NELSON, Ted. Libertando-se da prisão da Internet.In: FILE Symposium Proceedings, 2005, São Paulo, FILE Editorial, 2005. Disponível em: <http://dx.doi. org/10.13140/RG.2.2.20127.41126>. Acesso em: 12 dez. 2018.

RALEY, Rita. Mobile media poetics. UC Irvine: Digital Arts and Culture, 2009. Disponível em: <http://escholarship.org/uc/item/01x5vg8g>. Acesso em: 12 dez. 2018. 
DA SILVA, Cicero Inacio; MANOVICH, Lev. A era da infoestética. Entrevista com Lev Manovich. Revista Lumina. Juiz de Fora. v. 6, n. 01, Mar./Jul., 2012. Disponível em: <https://lumina.ufjf.emnuvens.com.br/lumina/article/view/232/227>. Acesso em: 12 dez. 2018.

STALBAUM, Brett. Locative media today. Cambridge: Leonardo/MIT Press, 2007.

WARDRIP-FRUIN, Noah. The new media reader. Cambridge: MIT Press, 2003. 